\title{
Medication withdrawal may be an option for a select group of patients in relapsing-remitting multiple sclerosis
}

\author{
Retirada de medicação pode ser uma opção para um grupo \\ selecionado de pacientes com esclerose múltipla remitente-recorrente \\ Guilherme Sciascia do Olival', Vitor Breseghello Cavenaghi², Vitor Serafim², Rodrigo Barbosa Thomaz', \\ Charles Peter Tilbery ${ }^{3}$
}

\begin{abstract}
This article describes the clinical and radiological evolution of a stable group of patients with relapsing-remitting multiple sclerosis that had their disease-modifying therapy (DMT) withdrawn. Forty patients, which had made continuous use of one immunomodulator and had remained free of disease for at least 5 years, had their DMT withdrawn and were observed from 13 to 86 months. Out of the followed patients, $4(10 \%)$ patients presented with new attacks. In addition to these patients, 2 (5\%) patients had new lesions revealed by magnetic resonance imaging that did not correspond to clinical attacks. Despite these results, the difficult decision to withdraw medication requires careful analysis. Withdrawal, however, should not be viewed as simply the suspension of treatment because these patients should be evaluated periodically, and the immunomodulators should be readily reintroduced if new attacks occur. Nonetheless, medication withdrawal is an option for a select group of patients.
\end{abstract}

Key words: multiple sclerosis, Therapeutics, multiple sclerosis, relapsing-remitting.

RESUMO

Esse artigo descreve a evolução clínica e radiológica de um grupo de pacientes com esclerose múltipla estável, forma recorrente-remitente, nos quais foi retirada a terapia modificadora da doença (DMT). Quarenta pacientes, que faziam uso contínuo de um imunomodulador e permaneceram livres da doença pelo menos por 5 anos, tiveram sua DMT retirada e foram observados de 13 a 86 meses. Dos pacientes seguidos, 4 (10\%) apresentaram novos surtos. Além destes, 2 (5\%) pacientes apresentavam novas lesões na ressonância magnética, sem sintomas clínicos. Apesar destes resultados, a retirada da medicação é uma decisão difícil, requer análise cuidadosa e não deve ser considerada como sinônimo de suspender o tratamento, já que estes pacientes devem ser avaliados periodicamente e o uso de imunomoduladores tem de ser prontamente reiniciado no caso do aparecimento de novos surtos. Não obstante, a retirada do medicamento é uma opção para um grupo selecionado de pacientes.

Palavras-Chave: esclerose múltipla, terapêutica, esclerose múltipla remitente-recorrente.

The use of disease-modifying therapy (DMT) for multiple sclerosis (MS) is consolidated. However, the discontinuation of DMT is still a controversial topic in the medical literature and is being offered to patients with progressive subtypes of the disease or under some special conditions, such as pregnancy, intolerable adverse effects, and psychiatric comorbidities. Recently, some authors proposed discussions regarding the withdrawal of DMT in stable patients with the relapsing-remitting (RR) subtype of $\mathrm{MS}^{1,2}$.

This article describes the clinical and radiological evolution of a stable group of patients with relapsing-remitting MS (RRMS) that had their DMT withdrawn.

Study carried out at Hospital da Santa Casa de São Paulo, São Paulo SP, Brazil.

${ }^{1}$ MD, Neurologist, Irmandade da Santa Casa de Misericórdia de São Paulo, São Paulo SP, Brazil;

${ }^{2}$ Medical Student, Santa Casa de São Paulo, Faculty of Medical Sciences, São Paulo SP, Brazil;

${ }^{3}$ MD, PhD, Full Professor, Santa Casa de São Paulo, Faculty of Medical Sciences, São Paulo SP, Brazil.

Correspondence: Guilherme Sciascia do Olival; Rua Guiratinga 58;04141-000 São Paulo SP - Brasil; E-mail: guilhermesolival@gmail.com / guiolival@yahoo.com.br Conflict of interest: There is no conflict of interest to declare.

Received 17 August 2012; Received in final form 30 January 2013; Accepted 06 February 2013. 


\section{METHODS}

This study was approved by the Santa Casa de São Paulo Research Ethics Committee.

We have followed a group of 40 patients prospectively that had stopped using immunomodulatory drugs between 2005 and 2011. The individuals had continuous use of the drugs from 5 to 14 years and had at least 5 years of diseasefree activity.

\section{Inclusion criteria}

We included patients with RRMS according to the 2005 revised McDonald diagnostic criteria ${ }^{3}$ that met the following conditions:

- Continuous use for at least 5 years of one of the following medications: $30 \mu \mathrm{g}$ of intramuscular IFN- $\beta$ la once a week, $300 \mu \mathrm{g}$ of subcutaneous IFN- $\beta$ lb every other day, 22 or $44 \mu \mathrm{g}$ of subcutaneous IFN- $\beta$ la 3 times a week or $20 \mathrm{mg}$ of subcutaneous glatiramer acetate daily;

- No clinical relapses;

- Stable burden of lesions on magnetic resonance imaging (MRI) exams for at least five years;

- An expressed desire to withdraw from medication after understanding all the risks involved.

\section{Exclusion criteria}

We excluded patients with:

- MS that had been previously submitted to immunosuppressive therapy;

- An aggressive clinical or radiological course;

- A progressive form of the disease;

- A history of DMT use that was less than 5 years.

\section{Follow-up}

The possibility of DMT suspension, as well as the risks, was presented to the selected individuals. The decision to withdraw DMT was made together with the patients.

After suspending medication, patients were evaluated every three months regarding the presence of symptoms indicative of a clinical relapse or an attack and were advised to seek our assistance if new symptoms ensued. Relapses were defined as new or recurrent neurologic symptoms not associated with fever or infection that lasted for at least 24 hours and were accompanied by new neurologic signs found by the examining neurologist. The Expanded Disability Status Scale (EDSS) ${ }^{4}$ was applied during each evaluation. An objective change in the neurologic examination consistent with an increase of at least a half-step on the EDSS or an increase of two points for one of the seven functional systems was used to confirm a relapse.

Disease-free activity was defined as no relapse, no sustained change in EDSS score, and no new MRI lesions (no T1 gadolinium-enhancing or active T2 lesions) over a specified period.
New MRI images were taken every six months and when a patient had a relapse. DMT was reintroduced in the event of a new attack or if the MRI evaluations showed a worsening.

\section{Statistical analysis}

The percentage of relapse-free patients after DMT withdrawal, the rate of EDSS stability and the percentage of disease-free activity patients after DMT withdrawal were analyzed.

A Kaplan-Meier curve was plotted to estimate the amount of patients that might remain relapse-free in a longer period. It was considered only the patients which follow-up length are included in the $95 \%$ confidence interval.

\section{RESULTS}

The patients were followed from 13 to 86 months, mean of 46.3 and median of 48 with standard deviation (SD) of \pm 16.3 months.

Out of the followed patients, 4(10\%) experienced new clinical relapses. In addition, 2 (5\%) patients showed new lesions in the MRI in T2 that did not correspond to clinical attacks. Fig 1 shows a timeline for each patient that delineates the period of continuous use of DMT, the period of suspended DMT and the period during which the relapse or MRI worsened occurred.

The 4 patients described above presented with new relapses after DMT withdrawal at 34, 46, 62 and 72 months, respectively. Three patients presented with sensitive symptoms, and one presented with motor symptoms. Only one patient had a persistent increase on the EDSS after the relapse; this patient increased from 1.0 to 1.5 .

The percentage of relapse-free patients after DMT withdrawal, the percentage of disease activity-free patients after DMT withdrawal, the prevalence of EDSS stability in these groups and other characteristics are shown in the Table. Fig 2 shows a Kaplan-Meier curve for the relapse rate among these patients.

\section{DISCUSSION}

The analysis of 40 patients, after DMT withdrawal with mean follow-up of 46.3 months, revealed $90 \%$ of attack-free patients; $85 \%$ of stable MRI after DMT withdrawal; $85 \%$ of disease activity-free patients and 97,5\% EDSS stability in patients.

Pitock et al. ${ }^{1}$ suggest that not all patients with MS should be treated with drugs because some patients have a mild form of the disease, and there are no consistent evidence of the long-term benefits of DMT. While 


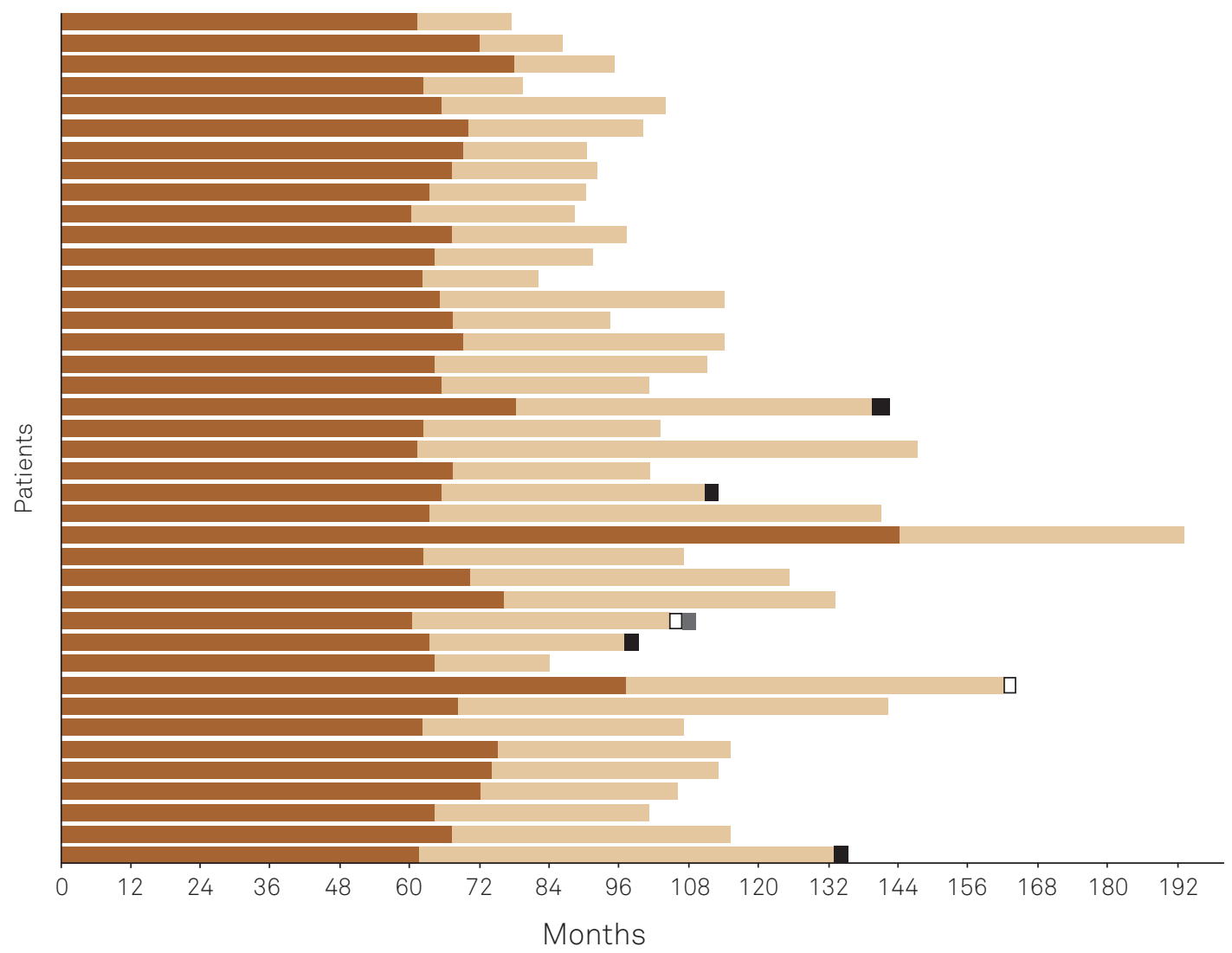

period of continuous use of DMT (in months)

period of suspended DMT (in months)

relapse

$\square$ MRI worsening

EDSS progression

DMT: disease-modifying therapy; EDSS: expanded disability status scale; MRI: magnetic resonance imaging.

Fig 1. Timeline discriminating in each patient period of use/suspension of disease-modifying therapy and clinical/magnetic resonance imaging worsening.

Table. Characteristics of the patients submitted to diseasemodifying therapy withdrawal.

\begin{tabular}{lc}
\hline Female & $36(90.0 \%)$ \\
Male & $4(10 \%)$ \\
Age at onset of disease (mean \pm SD, in years) & 29.2 \\
$\begin{array}{l}\text { Number of attacks prior to treatment } \\
\text { (mean } \pm \text { SD) }\end{array}$ & $2.7 \pm 1.0$ \\
$\%$ sensory attacks & 65.8 \\
$\%$ motor attacks & 7.9 \\
$\%$ other attacks (brain stem, cerebellum, & 26.3 \\
spinal cord) & \\
Time between disease onset and diagnosis & $57.6 \pm 53.1$ \\
(mean \pm SD, in months) & $69.1 \pm 19.6$ \\
Time of medication usage (mean $\pm S D$, in months) & $1.21 \pm 0.68$ \\
EDSS at beginning of treatment (mean $\pm S D)$ & $1.22 \pm 0.68$ \\
EDSS at the end of the study (mean $\pm S D$ ) & $46.3 \pm 16.3$ \\
Time without medication (mean $\pm S D$, in months) & $85.0 \%$ \\
Stable MRI after DMT withdrawal & $90.0 \%$ \\
Attack-free patients after DMT withdrawal & $85.0 \%$ \\
Disease activity-free patients after & $97.5 \%$ \\
DMT withdrawal & \\
EDSS stability in patients
\end{tabular}

DMT: disease-modifying therapy; EDSS: expanded disability status scale; MRI: magnetic resonance imaging; SD: standard deviation.
Kaplan-Meier curve of relapses in MS patients with the DMTs suspended

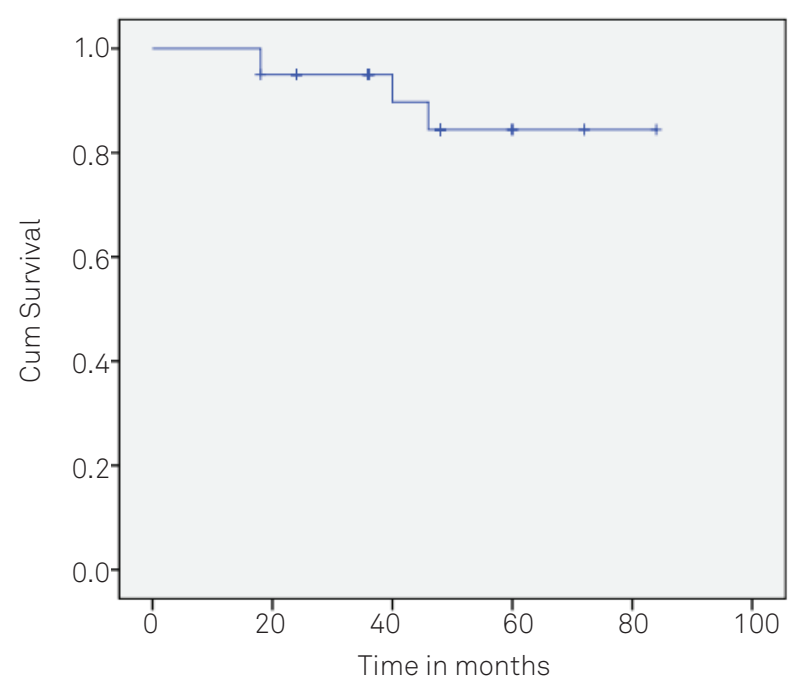

$\sqcap$ Survival Function $\quad+$ Censored

DMT: disease-modifying therapy; MS: multiple sclerosis.

Fig 2. Progress of the group of patients submitted to diseasemodifying therapy withdrawal. 
approximately $70 \%$ of patients with MS respond to treatment with immunomodulatory drugs, our group have demonstrated that the most effective use of DMT occurs in patients with high attack rates ${ }^{5}$. These medications do not seek to eliminate the occurrence of attacks but to diminish their frequency,7. Despite the recommendations of the consensus for the continual use of immunomodulatory drugs, the length of treatment needed to achieve the maximum benefit is uncertain because the periods of drug use are often longer than those of the clinical studies $^{8,9}$. Hence, the therapeutic effects of immunomodulatory drugs are well established in the short-term, but the long-term effects of these drugs are questionable ${ }^{10}$.

The prevalence of adverse effects associated with the immunomodulatory drugs ranges between 37.5 and $76 \%$, of which at least $20 \%$ of the cases are considered moderate or serious. The most common adverse effects of DMT are malaise, inflammatory reactions at the site of injection and flu-like reactions ${ }^{11,12}$. In the majority of cases, the adverse effects can be made more tolerable by therapeutic strategies and switching or suspending the medication is not necessary, although adverse effects are the main reasons for a lack of adherence to the treatment ${ }^{13-15}$. That being so the adherence to the treatment could improve if patients were advised about the possibility of DMT withdrawal according to the course of the disease.

An important issue that should also be considered is the economic impact of DMT use for both public and private health care systems. MS exerts a high cost burden for patients, health care systems and society ${ }^{16}$. The data obtained in the United States in 1994 points to an estimated individual cost of the disease over a patient's lifetime of approximately US\$ 2.2 million $^{17}$. The average annual individual cost of MS patients for the Brazilian public health care system was $R \$ 30,230.23$ in $2011^{18}$. In general, these costs are outweighed by the benefits when the treatment proves to be effective; however, our study suggests that DMT may not be necessary in all cases.

Favorable prognosis factors should be taken into account along with clinical and radiological stability (i.e., an amount of time that we considered to be five years) when suggesting DMT withdrawal. These factors include: full recovery after the first attack, long gaps between the first and second attacks, the first symptoms being of a sensory nature and the presence of few gadolinium-enhanced lesions on the basal MRI ${ }^{19-21}$. As seen in the Table, most of our patients had several favorable prognosis factors, such as presenting with a majority of sensory attacks (65.8\%) and a low baseline EDSS score at the beginning of treatment (1.21 on average). Only one patient had an EDSS increase of 0.5 points after the period studied (1.22 average EDSS score at the end of the period studied).

One of the limitations of our study is the lack of a control group with similar clinical characteristics to allow a statistical analysis of the safety of this approach.

When considering the lack of knowledge concerning the long-term benefits of DMT, the fact that DMT does not eliminate relapses, the effect of DMTs on patients with stable forms of the disease, the high costs of these drugs and their associated adverse events, it is logical to consider withdrawing these drugs in patients that are clinically and radiologically stable for long periods of time.

Despite our results, the decision to withdraw DMT is difficult and requires careful analysis. Withdrawal should not be viewed as a synonym of treatment suspension because patients undergoing withdrawal should be evaluated periodically, and immunomodulatory drugs should be readily reintroduced if new attacks should arise.

Further prospective studies with a larger number of patients and the presence of a control group are needed to better assess the safety of this approach to MS. Nonetheless, medication withdrawal may be an option for a select group of patients.

\section{References}

1. Pittock S, Weinshenker B, Noseworthy J, et al. Not every patient with multiple sclerosis should be treated at time of diagnosis. Arch Neurol 2006;63:611-614.

2. Multiple Sclerosis Therapy Consensus Group (MSTCG), Wiendl H, Toyka K, et al. Basic and escalating immunomodulatory treatments in multiple sclerosis: current therapeutic recommendations. J Neurol 2008;255:1449-1463.

3. Polman $\mathrm{CH}$, Reingold SC, Edan G, et al. Diagnostic criteria for multiple sclerosis: 2005 revisions to the "McDonald Criteria". Ann Neurol 2005;58:840-846.

4. Kurtzke J. Rating neurologic impairment in multiple sclerosis: an expanded disability status scale (EDSS). Neurology 1983;33:1444-1452.

5. Olival GS, Lima LCP, Lima GPS, Tilbery CP. Clinical predictors of response to immunomodulators for multiple sclerosis. Arq Neuropsiquiatr 2012;70:12-16.
6. Paty DW, Li DK. Interferon beta-1b is effective in relapsingremitting multiple sclerosis. II. MRI analysis results of a multicenter, randomized, double-blind, placebo-controlled trial. UBC MS/MRI Study Group and the IFNB Multiple Sclerosis Study Group. Neurology 1993;43:662-667.

7. Johnson KP, Brooks BR, Ford CC, et al. Sustained clinical benefits of glatiramer acetate in relapsing multiple sclerosis patients observed for 6 years. Copolymer 1 Multiple Sclerosis Study Group. Mult Scler 2000;6:255-266.

8. Sorensen PS,Koch-Henriksen N, RavnborgM, etal.Immunomodulatory treatment of multiple sclerosis in denmark: a prospective nationwide survey. Mult Scler 2006;12:253-264.

9. Brown MG, Kirby S, Skedgel C, et al. How effective are diseasemodifying drugs in delaying progression in relapsing-onset MS? Neurology 2007;69:1498-1507. 
10. Shirani A, Zhao Y, Karim ME, et al. Association between use of interferon beta and progression of disability in patients with relapsing-remitting multiple sclerosis. JAMA 2012;308:247-256.

11. Jordy SS, Tilbery CP, Fazzito MM. Immunomodulator therapy migration in relapsing remitting multiple sclerosis: a study of 152 cases. Arq Neuropsiquiatr 2008;66:11-14.

12. Bayas A, Rieckmann P. Managing the adverse effects of interferonbeta therapy in multiple sclerosis. Drug Saf 2000;22:149-159.

13. Río J, Porcel J, Téllez N, et al. Factors related with treatment adherence to interferon beta and glatiramer acetate therapy in multiple sclerosis. Mult Scler 2005;11:306-309.

14. Mohr DC, Boudewyn AC, Likosky W, Levine E, Goodkin DE. Injectable medication for the treatment of multiple sclerosis: the influence of self-efficacy expectations and injection anxiety on adherence and ability to self-inject. Ann Behav Med 2001;23: 125-132.

15. Mohr DC, Likosky W, Boudewyn AC, et al. Side effect profile and adherence to in the treatment of multiple sclerosis with interferon beta-1a. Mult Scler 1998;4:487-489.
16. Prescott JD, Factor S, Pill M, Levi GW. Descriptive analysis of the direct medical costs of multiple sclerosis in 2004 using administrative claims in a large nationwide database. J Manag Care Pharm 2007;13:44-52.

17. Whetten-Goldstein K, Sloan FA, Goldstein LB, Kulas ED. A comprehensive assessment of the cost of multiple sclerosis in the United States. Mult Scler 1998;4:419-425.

18. Brasil. Portal da Saúde. [cited 2012 Mar 15]. Available from: http:// portal.saude.gov.br/portal/saude/Gestor/area.cfm?id_area=939

19. Langer-Gould A, Popat RA, Huang SM, et al. Clinical and demographic predictors of long-term disability in patients with relapsing-remitting multiple sclerosis: a systematic review. Arch Neurol 2006;63: 1686-1691.

20. Confavreux C, Vukusic S, Adeleine P. Early clinical predictors and progression of irreversible disability in multiple sclerosis: an amnesic process. Brain 2003;126:770-782.

21. Tintoré M, Rovira A, Río J, et al. Baseline MRI predicts future attacks and disability in clinically isolated syndromes. Neurology 2006;67:968-972. 